\title{
LEFT VENTRICULAR EJECTION FRAGTION AFTER ACUTE MYOCARDIAL INFARCTION.
}

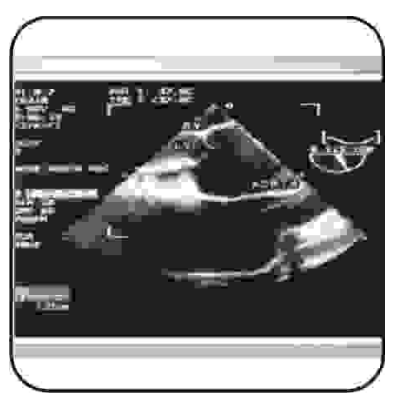

\author{
DR. HAFIZ MUGHEES ATHER \\ MBBS, FCPS, MRCP \\ Assistant Consultant Internal Medicine \\ King Khalid National Guard Hospital Jeddah, \\ Saudi Arabia.
}

\begin{abstract}
Objective: (1). To measure and compare Left Ventricular Ejection Fraction (LVEF) after acute anterior wall and inferior wall myocardial Infarction and correlate LVEF with clinical findings in the patients. (2) To see prevalence of Left Ventricular Failure (LVF) after AMI. Design: Prospective observational echocardiography based study. Setting: Sheikh Zayed Hospital Lahore. Period: From 2001 to 2002. A total of 60 (sixty) patients of (anterior or inferior) Acute Myocardial infarction (AMI) were included in the study. Patients were divided in two groups on the basis of anterior myocardial wall MI (AWMI) or inferior myocardial wall MI (IWMI). Echocardiography was done on all cases and ejection fraction was calculated by applying Simpson's Rule and patients were examined at the same time to see the presence of signs of left ventricular failure (LVF). (LVEF) was correlated with the findings of LVF in these patients. Results: In patients with LVF mean ejection fraction (EF) was 37.13 with standard deviation (SD) of $8.4 \%$. In patients without failure the mean EF was $56.29 \%$ with SD of 3.75 . In 30 patients of IWMI, mean EF was $54.93 \%$ with SD of 6.86 . In 30 patients of AWMI it was $46.07 \%$ with SD of 11.72 . In all 60 patients minimum EF was $30 \%$ and maximum was $60 \%$ with a mean of 50.50 with SD of 10.52 . In AWMI, $53 \%$ patients had signs of left ventricular failure. In patients of IWMI, $13.3 \%$ had signs of LVF. Conclusions: AWMI causes more decrease in LVEF. LVF is more commonly associated with AWMI than IWMI. There is statistically significant difference in LVEF of patients with and without LVF.
\end{abstract}

Key words: Acute myocardial infarction, left ventricular failure, left ventricular ejection fraction, echocardiography

\section{INTRODUCTION}

At the beginning of $20^{\text {th }}$ century, ischemic heart disease (IHD) accounted for less than $10 \%$ of all deaths worldwide. At its end, it accounted for nearly half of all deaths in the developed world and $25 \%$ in developing world ${ }^{1}$.
IHD will claim 25 million deaths annually and it will surpass infectious diseases as world's number one cause of death and disability in future. It will be accounting for $36.3 \%$ of all deaths by year 2020 .

AMl continues to be a major health problem and one of the most common diagnoses in hospitalized patients in 
industrialized world. In US 1.5 million patients suffer from AMl every year (one patient in every 20 minutes) ${ }^{1}$. When myocardium undergoes ischemic injury, left ventricular pump function becomes depressed, cardiac out put, stroke volume, and BP is decreased. AMI frequently causes heart failure, characterized by either systolic dysfunction alone or by both systolic and diastolic dysfunction. Heart failure has increased risk of mortality. LV dysfunction and increased systolic volume are important predictors of mortality after $\mathrm{AMI}^{1}$. LV diastolic dysfunction leads to pulmonary congestion and pulmonary venous hypertension whereas systolic dysfunction is principally responsible for the depression of cardiac out put and of ejection fraction. Clinical manifestations of LV failure become more common as the extent of the injury to LV increases. In addition to infarct size, the important predictors of the development of symptomatic LV dysfunction include age and DM. Mortality increases in association with the severity of the hemodynamic deficit.

Echocardiography is a standard tool in the management of patients with AMI. With color flow Doppler it can assess left and right ventricular function, and other important cardiac parameters. It is usually the preferred test to measure the LVEF, since it can detect other abnormalities that are associated with a worse prognosis including diastolic dysfunction, concurrent right ventricular involvement, increased left atrial volume, mitral regurgitation, and a high wall motion score index. (LVEF) is a major predictor of long-term prognosis after both ST elevation and non-ST elevation infarctions. For those with an LVEF $<28$ percent, survival at one year is 24 percent (versus 56 percent for those with a higher LVEF).

The 2003 American Heart Association task force gave a class I recommendation to the use of echocardiography for the in-hospital assessment of ventricular function after AMI.

This study was single center, echocardiography based, observational study.

The purpose of study was

1. To measure and compare LVEF after acute anterior wall and inferior wall myocardial Infarction.

2. To correlate LVEF with clinical findings in the patients.

3. To see prevalence of left ventricular failure (LVF) after AMI.

4. To identify those patients who are more prone to develop LVF after AMI, so that extra precautionary measures can be taken to prevent it.

\section{MATERIALS AND METHODS}

It was a prospective observational echocardiography based study which was carried out in the department of coronary care unit at Sheikh Zayed Hospital Lahore from 2001 to 2002.

All the patients with isolated acute anterior or inferior wall myocardial infarction that present within five days of onset of symptoms were included in the study. There was no discrimination for age and sex. The diagnostic criteria for myocardial infarction were presence of any two (2) of the followings:

i. History suggesting AMI,

ii. $\quad$ ECG changes in anterior or inferior leads suggesting acute Ml of that area.

iii. Raised cardiac enzymes.

Following patients were excluded from the study.

1. Patients having evidence of previous myocardial infarction by history or ECG.

2. Patients who were having all other MI or presented later than five days of onset of severe symptoms.

3. Patients having combined anterior and inferior wall Ml or with non-Q wave MI.

4. Patients having isolated pericardial disease, gross valvular heart disease, inflammatory heart disease because these conditions independently decrease EF, however presence or absence of signs of LVF was not an inclusion or exclusion criteria.

A total of 60 patients, 30 consecutive patients of each 
type (anterior or inferior) of AMI were under study. Patients were divided in two groups. One group included patients of AWMI (group I), and other included patients of IWMI (group II). Echocardiography was done on all cases on the fifth post MI day. Left ventricular internal diameter during diastole as well as during systole were measured by applying Simpson's Rule and ejection fraction was calculated in apical two chamber and four chamber views separately. Mean ejection fraction was calculated. Patients were examined at the same time to see the presence of signs of LVF. Patients in each group were further subdivided into two groups each based on the clinical signs of LVF. Group la and Ila were having signs of left ventricular failure and groups $\mathrm{lb}$ and $\mathrm{llb}$ having no findings of LVF. Mean LVEF and standard deviation for each group was calculated and compared by applying independent sample t-test. Group comparison of mean LVEF was done. Proportion of the patients with left ventricular failure was calculated in each group and compared by using chi-square test.

LVEF of patients with failure was compared with LVEF of patients without failure by using independent sample ttest. Similarly age of all patients was compared collectively and separately in anterior and inferior wall MI. Sex proportion of patients of both groups of anterior wall and inferior wall MI was noted separately and collectively.

\section{INSTRUMENT (ECHO MACHINE)}

The echocardiography machine of department of cardiology was used for calculation of LVEF. This is high technology stuff with built-in computer and advanced software.

\section{RESULTS}

In 30 patients of anterior wall MI, $18(60 \%)$ were male and $12(40 \%)$ were female. In inferior wall MI, 28 (93.3\%) were male and $2(6.7 \%)$ were female. In all 60 patients $(76.7 \%)$ patients were male and $(23.3 \%)$ were females. In anterior wall $\mathrm{MI},(6.7 \%)$ were in 30 to 40 years of age, (33.3\%) were in 41 to 50 years of age, (33.3) were in 51 to 60 years of age, $(20.0 \%)$ were in 61 to 70 years of age, and $(6.7 \%)$ were in 71 to 80 years of age. Minimum age was 39 years; maximum was 72 years, with mean of
54.57 and SD of 9.22. In inferior wall MI, (13.1\%) were between 30 to 40 years, (23.3\%) were between 41 to 50 years, $(40.0 \%)$ were between 51 to 60 years, and (3.3\%) were between 71 to 80 years. Minimum age was 38 years; maximum was 71 years with mean of 52.50 and SD of 9.69. In all 60 patients, (10\%) patients were in age group of 30 to 40 years, $(28.3 \%$ ) patients were in 41 to 50 years, $22(36.7 \%)$ were in 51 to 60 years. $(20 \%)$ were in 61 to 70 years. (5\%) were in 71 to 80 years (Table-I).

In anterior wall $\mathrm{MI},(6.7 \%)$ had $30 \% \mathrm{EF},(6.7 \%)$ had $31 \%,(20 \%)$ had $32 \%,(6.7 \%)$ had $32 \% \mathrm{EF},(6.7 \%)$ had EF of $45 \%,(6.7 \%)$ had $52 \%,(6.7 \%)$ had $53 \%,(6.7 \%)$ had EF of $54 \%$, and another (6.7 \%) had $56 \%$ $\mathrm{EF},(13.3 \%)$ had EF of $57 \%$ and lastly 2 patients having EF of $64 \%$. The mean EF was $46.07 \%$ with standard deviation of 11.72 .

In 30 patients of inferior wall $\mathrm{MI},(6.7 \%)$ had EF of $39 \%$, $(13.3 \%)$ had $49 \%,(20 \%)$ had $52 \%$, and $(13.3 \%)$ had $55 \%,(13.3 \%)$ had $56 \%$, (13.3\%) had $57 \%$, $(6.7 \%)$ had $62 \%,(6.7 \%)$ had $65 \%$ and $(6.7 \%)$ had $68 \%$ EF. Mean EF was $54.93 \%$ with standard deviation of 6.86 . In all 60 patients minimum EF was $30 \%$ and maximum EF was $60 \%$ with a mean of 50.50 with standard deviation of 10.52(Table-II).

In $4(13.3 \%)$ patients of IWMI who were having cardiac failure clinically, minimum EF was $39 \%$ and maximum was $49 \%$, mean of $44 \%$ with SD of 5.77 . In $26(86.7 \%)$ patients without failure, minimum EF was $49 \%$ and maximum EF was $68 \%$ mean of $56.62 \%$ and SD of 5.34 . In 16 patients (53.0\%) of AWMI who were having failure clinically, minimum EF was $30 \%$ and maximum was $54 \%$, mean of $37.13 \%$ with SD of 8.4 . In $26(86.7 \%)$ patients without failure, minimum EF was $49 \%$ and maximum EF was $68 \%$ mean of $56.62 \%$ and SD of 5.34(Table-IV \& V).

In all patients with failure, mean EF was 37.13 with SD of 8.4 and min. was $30 \%$ and max was $54 \%$. In patients without failure the mean EF was $56.29 \%$ with SD of 3.75 , and $\min$. of $52 \%$ and max was $64 \%$ (Table-VI). 


\begin{tabular}{|l|c|c|c|c|c|}
\hline & Minimum & Maximum & Mean & SD & P value \\
\hline Anterior wall MI & 39 & 72 & 54.47 & 9.22 & 0.62 \\
\hline Inferior wall MI & 38 & 71 & 52.50 & 9.69 & \\
\hline
\end{tabular}

\begin{tabular}{|l|c|c|c|c|c|}
\hline \multicolumn{5}{|c|}{ Table-II. Comparison of LVEF in anterior and } \\
inferior wall MI \\
\hline $\begin{array}{c}\text { Type of } \\
\text { MI }\end{array}$ & \multicolumn{4}{|c|}{ Left ventricular ejection fraction } \\
\cline { 2 - 6 } & Min & Max & Mean & SD & P value \\
\hline $\begin{array}{l}\text { Anterior } \\
\text { wall MI }\end{array}$ & 30 & 64 & 46.07 & 11.72 & \multirow{2}{*}{$<0.001$} \\
\hline $\begin{array}{l}\text { Inferior } \\
\text { wall MI }\end{array}$ & 39 & 68 & 54.93 & 6.68 & \\
\hline
\end{tabular}

\begin{tabular}{|l|c|c|c|}
\hline \multicolumn{2}{|c|}{ Table-III. Proportion of patients with LVF } \\
\hline \multirow{2}{*}{} & \multicolumn{3}{|c|}{ LVF Present } \\
\cline { 2 - 4 } & Yes & No & P-value \\
\hline Anterior wall MI & 16 & 14 & \multirow{2}{*}{0.001} \\
\hline Inferior wall MI & 04 & 26 & \multirow{2}{*}{0.001} \\
\hline Total & 20 & 40 & \\
\hline
\end{tabular}

\begin{tabular}{|c|c|c|c|c|c|}
\hline & Min & Max & Mean & SD & $P$ value \\
\hline $\begin{array}{l}\text { Patients with } \\
\text { failure }\end{array}$ & 30 & 54 & 37.13 & 8.4 & \multirow{2}{*}{0.001} \\
\hline $\begin{array}{l}\text { Patients } \\
\text { without failure }\end{array}$ & 52 & 64 & 56.29 & 3.75 & \\
\hline
\end{tabular}

\begin{tabular}{l} 
Table-V. Left ventricular ejection fraction in patients with \\
and without LVF in inferior wall MI \\
\hline
\end{tabular}

\section{Table-VI. LVEF in patients with and without failure}

\begin{tabular}{|l|c|c|c|c|}
\cline { 1 - 3 } LVF & No. of patients & Mean LVEF & SD & P value \\
\hline Yes & 20 & 38.50 & 8.30 & \multirow{2}{*}{0.001} \\
\cline { 1 - 3 } No & 40 & 56.50 & 4.80 & \\
\hline
\end{tabular}

\section{DISCUSSION}

It was noted that patients of AWMI had more decrease in LVEF as compared to patients with IWMI. More over larger proportion of patients of AWMI had clinically and statistically significant LVF. In the study of Awan ZA ${ }^{2}$ et al among 210 patients $76 \%$ were males and $24 \%$ were females. In studies conduced such as Haq et $\mathrm{al}^{3}$, mean age was 54 years. In our study mean age was 53 years. In our study males were $76 \%$ and females were $23 \%$. In anterior wall MI, 18 patients (30\%) were males and 12 patients (40\%) were female. In inferior wall MI, 28 (93\%) were male and 2 patients $(7 \%)$ were females. There were $79 \%$ males and $21 \%$ were females in the study of Haq et $\mathrm{al}^{3}$. Males and females were in the proportion of 3:1 in the study of Karim $\mathrm{MA}^{4}$ and co-workers. In our study, about $53 \%$ of patients had LVF clinically in anterior wall MI and about $13 \%$ of patients in inferior wall MI with overall proportion of $33 \%$ in all patients. Whereas the percentage of patients having failure was $43 \%$ without mentioning the type of Ml. in the study of Kyne $L^{5}$ and coworkers.

The mean LVEF was $47 \%$ in study of Sola $\mathrm{M}$ et $\mathrm{al}^{6}$ without mentioning the type of Ml from which the patients were suffering. In our study mean LVEF was $46 \%$ in anterior wall $\mathrm{Ml}$ and $54 \%$ in inferior wall $\mathrm{Ml}$ and mean of all patients was $50 \%$. LVEF decreased to $45 \%$ in the study of Senior $\mathrm{R}^{7}$ and Coworkers. Ali $\mathrm{AS}^{8}$ and co workers made pulmonary rales, S3 gallop, and interstitial edema on the chest radiograph the criteria for the presence or absence of left ventricular failure and 
labeling a patient in LVF. In my study vital signs especially pulse, blood pressure, and respiratory rate were also included in the criteria. In the study of Ali AS et $\mathrm{al}^{8}, 43 \%$ patients had LVF, whereas in our study $54 \%$ and $13 \%$ patients had LVF in AWMI and IWMI respectively. In the study of $A$ wan $Z A^{2}, 29 \%$ patients had sign and symptoms of left ventricular failure. VAUR $L^{9}$ noticed mean LVEF of $50 \%$ in patients of AMI, and $17 \%$ patients had clinical failure with 35\% LVEF. My findings of increased incidence of LVF in patients with AWMI are consistent with the findings of Vaur L. Darbar $D^{10}$ noticed that anterior infarction causes more decrease in LVEF and our findings are consistent with it. He also had the findings that the patients in which signs and symptoms of LVF are present have mean LVEF of $40 \%$, in my studies these patients have mean LVEF of $37.13 \%$ in patients of anterior $\mathrm{MI}$, and $44 \%$ in patients of inferior MI with SD of 8.4 and 5.77 respectively.

The clinical presence of LVF (killip class > 1) was noted in about $50 \%$ of cases in study of Poulsen $\mathrm{SH}^{11}$, whereas in my study it is present in $53 \%$ of AWMI and $13 \%$ of patients with IWMI and $33 \%$ of all cases. But the clear cut difference in the clinical and echocardiographical findings between the patients of anterior wall MI and that of inferior wall Ml are not noted in the recent data, neither it is documented in the studies conducted in Pakistan. So our study is new in this aspect especially in Pakistan.

Councelo $\mathrm{J}^{12}$, found that Simpson's rule is the method of choice for calculating LV volumes and he has recommended this method for calculating left ventricular volumes and LVEF, this method is used in our study for calculating left ventricular volume and left ventricular ejection fraction. Moreover it is more commonly employed method as stated in the study of Yvorchuck $\mathrm{KJ}^{13}$. In my study inferior wall MI were more frequent than anterior wall MI. When 30 patients of inferior wall MI were completed and enrolled about 20 patients of anterior wall MI were enrolled at that time. But in the study of Awan $\mathrm{ZA}^{2} 56 \%$ were of anterior wall $\mathrm{Ml}$ and $12 \%$ patients were of inferior wall Ml. We used the criteria of prolonged chest pain for more than 45 minutes, typical ECG changes of $\mathrm{AMI}$, and raised cardiac enzymes for the diagnosis of acute myocardial infarction. These all criteria were also used in the study of Awan ZA.

\section{CONCLUSIONS}

1. Anterior wall Ml causes more decrease in LVEF.

2. Left ventricular failure is more commonly associated with anterior wall MI than inferior wall Ml.

3. There is statistically significant difference in LVEF of patients with LVF and without LVF.

4. Male gender is more common among patients of acute myocardial infarction

5. $\mathrm{Ml}$ is more common in $6^{\text {th }}$ decade of life.

\section{REFERENCES}

1. Antman EM, Braunwald E. Acute myocardial infarction. In: Braunwald E, Fauci AS, Isselbacher KJ, Wilson JD, Martin JB, Kasper DL et al eds. Harrison's Principles of internal medicine .New York: McGraw-Hill, 1998: 1352-65.

2. Awan ZA, Mufti W. First year mortality and morbidity after AMI in Peshawar. J Ayub Med Coll 1996; 8: 3-5.

3. Haq I. In-hospital mortality after acute myocardial infarction. Specialist, 1993; 9: 249-51.

4. Karim MA, Mehmood SF, Akhtar J, Qureshi J. Thrombolytic therapy in AMI in Pakistan. J Pak Med Assoc. 1995; 45: 54-8.

5. Kyne L, Hausdorff JM, Knight E, Dukas L, Azhar G, Wei JY. Neutrophilia and congestive heart failure after acute myocardial infarction. Am Heart J. 2000; 139: 94100.

6. Sola M, Margrina J, Pavia J, Vidal-Sicart S, Huguet M, Pare $C$, et al. Predictive value of $99 \mathrm{Tcm}-$ Sestamibi gated SPECT for long-term myocardial perfusion and recovery after acute myocardial infarction. Nucl Med Commun 1998; 19: 823-30.

7. Senior R, Basu S, Kinsey C, Schaeffer S, Lahiri A. Carvedilol prevents remodeling in patients with left ventricular dysfunction after acute myocardial infarction. Am Heart J 1999; 137 (4 pt.1): 646-52.

8. Ali AS, Rybicki BA, Alam M, Wulbercht N, Kicher-Cornish$\mathrm{K}$, Khaja $\mathrm{F}$, et- al. Clinical predictors of heart failure in patients with first acute myocardial infarction. Am Heart J 1999; 138: 1133-9.

9. Vaur L, Danchin N, Genes N, Renault M,etienne S, 
Ferriers, et al. Characteristics of patients hospitalized for myocardial infarction in France with respect to left ventricular dysfunction. Arch Mal Coer-Vaiss. 1997. 11: 1485- 92.

10. Darbar D, Gillepsie N, Choy AM, Lang CC, Pringle SD, and Pringle $\mathrm{TH}$ et al. Diagnosing left ventricular dysfunction after myocardial infarction: the Dundee algorithm. QJM 1997; 90:677-83.

11. Poulsen SH, Jensen SE, Egstrup K. Longitudinal changes and prognostic implications of left ventricular diastolic function in first acute myocardial infarction. Am Heart J. 1999; 137: 910-8.

12. Coucelo J, Joaquim N. Calculation of volumes and systolic indices of heart ventricle from Halobatrachus didactylus. J Exp Zool. 2000; 286: 585 -95.

13. Yorchuk KJ, Davies RA, Chang KL. Measurement of left ventricular ejection fraction by acoustic quantification and comparison with radionuclide angiography. $A m \mathrm{~J}$ Cardiol. 1994; 74: 1052-56.

\section{$\# 03$ \\ URO - PREGNANCY}

SAJIDA ASGHAR

$27 \gamma$

W/O MUHAMMAD ASGHAR

WARD NO.4 MOGHAL HOUSE.

SANGLAHILL

LMP Dec-05

EDD Sep-06

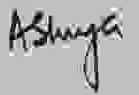

- Free consultation by medical officers

- 24 hours service throughout the year

- Emergency services

- $100 \%$ discount on medical officer fee on hospitalization

\section{SHAFFE MEDICAL CENTRE}

175. JININAH COLOINY. FAISALABAD

TEL. +92 41 2617122-24. FAX +92 41 2623413 shulatahir@luhrospital.com 